\title{
Международная конференция „Механизмы и нелинейные проблемы нуклеации, роста кристаллов и тонких пленок“, посвященная памяти выдающегося физика-теоретика профессора В.В. Слёзова
}

\author{
(С) Л.Н. Давыдов ${ }^{1}$, С.А. Кукушкин ${ }^{2, \uparrow}$ \\ ${ }^{1}$ Институт теоретической фризики им. А.И. Ахиезера Национального научного центра \\ „Харьковский физико-технический институт“ (ННЦ ХФТИ), \\ Харьков, Украина \\ ${ }^{2}$ Институт проблем машиноведения РАН, \\ Санкт-Петербург, Россия \\ `E-mail: sergey.a.kukushkin@gmail.com
}

Поступила в Редакцию 16 июля 2019 г. В окончательной редакции 16 июля 2019 г. Принята к публикации 25 июля 2019 г.

Настоящий выпуск журнала „Физика твердого тела“ публикует труды международной конференции „Механизмы и нелинейные проблемы нуклеации, роста кристаллов и тонких пленок (International conference «Mechanisms and Non-linear Problems of Nucleation and Growth of Crystals and Thin Films" (MGCTF 2019))»,посвященной памяти выдающегося физика-теоретика Виталия Валентиновича Слёзова.

Ключевые слова: фазовые переходы, Освальдовское созревание, теория Лифшица-Слёзова, нелинейные проблемы нуклеации, рост кристаллов и пленок.

DOI: $10.21883 /$ FTT.2019.12.48531.01ks

Конференция проходила с 1 по 5 июля 2019 г. в г. Санкт-Петербурге в Санкт-Петербургском центре РАН. В работе конференции приняли участие более 230 ученых из 21 одной страны мира. Она была посвящена анализу фундаментальных проблем фазовых переходов первого рода. Симпозиум продолжил и объединил традиции, начатые ранее двумя международными конференциями, посвященными этой проблеме. Одна из этих конференций „Nucleation and non-linear problems in first-order phase transitions" (NPT) проводилась в 1998 (NPT98) и 2002 (NРT2002) в Санкт-Петербурге и была организована Лабораторией структурных и фазовых превращений в конденсированных средах Института проблем машиноведения РАН (проф. С.А. Кукушкин, Санкт-Петербург), вторая - международный симпозиум „Nucleation theory and applications“ проводилась 20 лет подряд, начиная с 1997 г. (1997-2016) и была организованна Лабораторией теоретической физики им. Н.Н. Боголюбова Объединенного института ядерных исследований (проф. Вячеслав Б. Приезжев, г. Дубна) совместно с Институтом физики Ростокского университета (проф. Jürn W. P. Schmelzer, г. Росток, Германия). Эти две конференции охватывали практические все основные мировые тенденции и направления фундаментальных проблем кинетической теории фазовых переходов первого рода. Постоянным участником, пленарным докладчиком и научным „мэтром“ этих конференций был проф. Виталий Валентинович Слёзов. Проф. В.В. Слёзов совместно с И.М. Лифшицем является создателем знаменитой теории коалесценции (Ostwald ripening) Лифшица-Слёзова. Основной целью конференции „Механизмы и нелинейные проблемы нук- леации, роста кристаллов и тонких пленок“ являлось продолжение и развитие традиций начатых конференциями „Nucleation theory and applications“ проводимыми в г. Дубне и конференцией „Nucleation and non-linear problems in first-order phase transitions“, проводимой в Санкт-Петербурге, также почтить память нашего Учителя и наставника проф. В.В. Слёзова.

Область применения фазовых переходов за последние годы существенно расширилась. Фундаментальные проблемы образования новой фазы, возникающие при синтезе новых материалов, наноструктур, нитевидных кристаллов требуют развития новых глубоких подходов, основой которых является фундамент теории фазовых переходов, созданный трудами таких ученых как: Дж. Гиббс, М. Фольмер и А. Вебер, Б. Беккер и Д. Дёринг, Я. Френкель, Я. Зельдович, И. Лифшиц, В. Слёзов и Ф. Куни.

Важнейшей целью данной конференции являлось объединение специалистов, работающих в области чистой теории фазовых переходов, с технологами и экспериментаторами, выращивающими кристаллы и пленки. Мы надеемся, что прошедшая конференция помогла специалистам существенно продвинуться в понимании сложных процессов, протекающих в процессе синтеза и получения новых инновационных материалов. Конференция позволила установить прямое сотрудничество между ведущими учеными и научными группами и создать условия для будущей совместной работы. В большинстве докладов обсуждались новые перспективные направления по росту пленок, кристаллов и наноструктур. Много внимания было уделено процессам, протекающим при фазовых переходах в атмосфере и биологии. 
Обсуждались проблемы фазовых превращений в живых системах и клетках крови.

В данных системах, на поздней стадии фазовых переходов, эволюция зародышей новой фазы, как и в любых других системах, подчиняется закону ЛифшицаСлёзова, который является путеводной звездой для исследователей при их продвижении сквозь сложные многофакторные процессы образования новой фазы. Теория Лифшица-Слёзова описывает один из фундаментальных процессов кинетики фазовых превращений, а именно,позднюю стадию фазовых переходов первого рода, так называемый процесс Ostwald ripening. Открытый И.М. Лифшицем и В.В. Слёзовым закон эволюции ансамблей зародышей новой фазы на поздней стадии имеет универсальный вид и описывает поведение ансамблей зерен новой фазы в любых системах.

В 2018 г.исполнилось 60 лет с момента создания теории Лифшица-Слёзова, одним из создателей которой являлся выдающийся физик-теоретик, профессор, членкорреспондент Национальной академии наук Украины Виталий Валентинович Слёзов, которому в марте следующего 2020 г. исполнилось бы 90 лет со дня рождения (рис. 1).

В.В. Слёзов родился 9 марта 1930 г. в г. Сокол Вологодской области в семье служащих. Мать, Вера Михайловна, была бухгалтером, а отец, Валентин Петрович, работал в бумагоделательной промышленности и вскоре после рождения сына был переведен в Ленинград. Детство Виталия Валентиновича пришлось на трудное предвоенное время и годы Великой Отечественной войны. В 1941 г. его эвакуируют из блокадного Ленинграда с одной из последних групп детей. В эвакуации он находился в городе Шарья Горьковской области и в 1944 г. вернулся в Ленинград.

В 1948 г. Виталий Валентинович поступает на физикомеханический факультет Ленинградского политехнического института,который заканчивает в 1953 г. Однако тематика, которой ему предложили заниматься в Ленинграде, его не заинтересовала. В это же время он узнал, что существует возможность заниматься теорией твердого тела в Украинском Физико-техническом институте (УФТИ) в г. Харьков.

Его переезд оказался счастливым - в Харькове состоялась его встреча с Учителем - выдающимся физикомтеоретиком Ильей Михайловичем Лифшицем, который в то время возглавлял Отдел теории твердого тела УФТИ (рис. 2).

Первые опубликованные работы Виталия Валентиновича были посвящены теории металлов [1,2]. Затем перед начинающим ученым И.М. Лифшиц поставил задачу высокой сложности - создание теории так называемого Оствальдовского созревания (в отечественной традиции используется также термин „коалесценция“) на примере диффузионного распада твердых растворов с образованием выделений новой фазы.

Физической причиной этого явления является известный эффект, когда локальное равновесие у поверхности

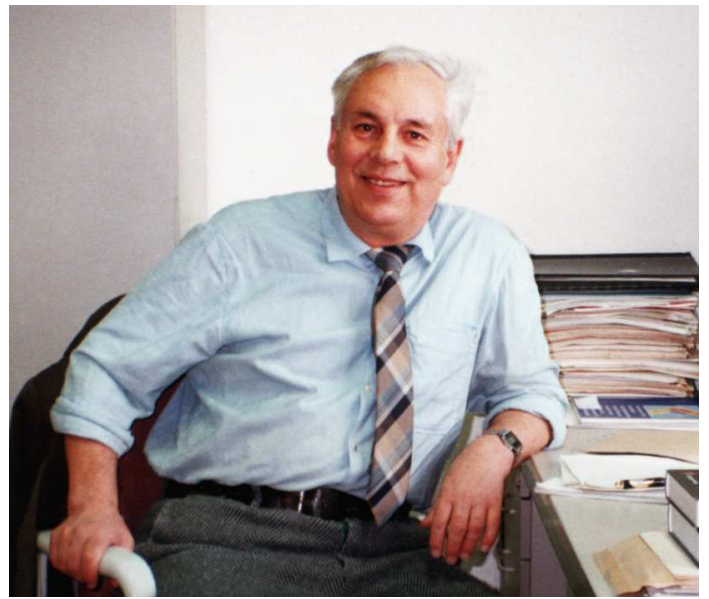

Рис. 1. Виталий Валентинович Слёзов. 09.03.1930-30.10.2013.

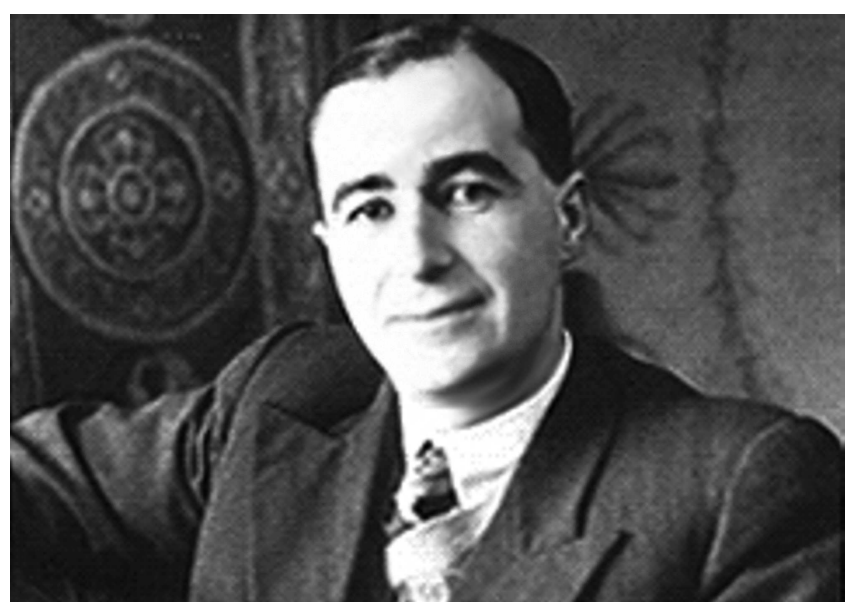

Рис. 2. Илья Михайлович Лифшиц. 13.01.1917-23.10.1982.

выделения новой фазы зависит, благодаря поверхностному натяжению межфазной границы, от кривизны этой границы и, следовательно, от размера выделений. Тем самым, раствор может быть пересыщенным для больших частиц и одновременно недосыщенным для малых, в силу чего большие выделения в растворе продолжают расти,а малые - растворяются. Это приводит к весьма сложной нелинейной кинетике процесса.

Несмотря на предпринимавшийся прежде попытки,решить данную задачу не удавалось. Справедливости ради следует отметить, что первый кто отметил важность этой задачи был Оскар Моисеевич Тодес (рис. 3).

В работе [3] он впервые вывел полную систему уравнений, описывающих начальную, переходную и заключительную стадии процесса образования новой фазы из растворов. Стадию Оствальдовского созревания он называл стадией „перегонки“ (в последствии Федор Максимилианович Куни назовет эту стадию стадией „переконденсации“). В этой работе он впервые показал, что пересыщение $\xi(t)$ в растворе и критический радиус 
$R_{\mathrm{cr}}(t)$ зародышей на этой стадии уменьшаются со временем $t$ в соответствии с законами

$$
\begin{aligned}
& \xi(t) \sim t^{-1 / 3}, \\
& R_{\mathrm{cr}}(t) \sim t^{1 / 3} .
\end{aligned}
$$

O.M. Тодес, кроме того, высказал и предположение, что на асимптотической стадии должно формироваться универсальное распределение зародышей новой фазы по размерам. Хочется отметить, что эти две работы O.M. Тодеса предвосхитили многие последующие идеи и работы по теории фазовых переходов. В частности, в этой же статье [3] О.М. Тодес впервые поставил задачу и необходимости учета переходной стадии зародышеобразования, которую впоследствии развивал Ф.М. Куни и его школа [4].

Результатом работы И.М. Лифшица и В.В. Слёзова явилась знаменитая теория Лифшица-Слёзова („LS-теория“), опубликованная в серии статей, начиная с 1958 г. В первой фундаментальной работе „О кинетике диффузионного распада пересыщенных твердых растворов“ [5] была получена система уравнений, описывающих кинетику диффузионного распада пересыщенных примесью твердых растворов. Это существенно нелинейная интегро-дифференциальная система для зависящих от времени функции распределения выделений новой фазы по размерам и пересыщенности в системе. Тонкий анализ возможных решений позволил найти асимптотическую (по времени) функцию распределения по размерам и описать поведение пересыщенности со временем. Замечательным результатом явилась универсальность этого решения и его независимость от начальных условий, в том числе и от начального распределения выделений новой фазы по размерам.

В следующей работе [6] был снят ряд упрощающих допущений, использовавшихся в первой работе, в частности, описано слияние растущих частиц новой фазы, учтена роль упругих напряжений и несферичности частиц. Расширенное изложение результатов работ $[5,6]$ с подробным описанием метода решения приведено в статье [7], опубликованной в 1961 г. В этом же году была опубликована статья известного немецкого физикохимика К. Вагнера (C. Wagner)[8], который сославшись на работы О.М. Тодеса, И.М. Лифшица и В.В. Слёзова рассмотрел дополнительный случай эволюции ансамбля частиц новой фазы, в при котором рост частиц новой фазы лимитируется граничной кинетикой. К. Вагнер знал русский язык и поэтому легко ознакомился с содержанием статей [5]. В своей статье он привел подробное описание результатов работы [5]. Для решения своей задачи Вагнер полностью воспользовался и развитым в работе Лифшица-Слёзова [5] математическим аппаратом решения систем уравнении эволюции новой фазы и методом их анализа. К сожалению, в зарубежной литературе, не вполне справедливо, за теорией Лифшица-Слёзова

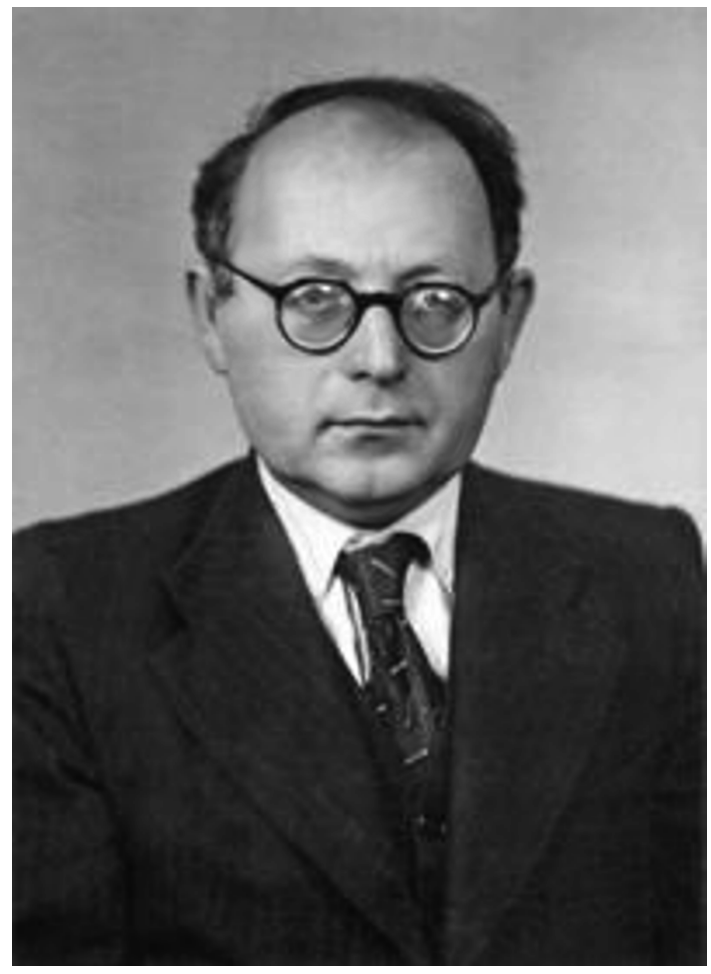

Рис. 3. Оскар Моисеевич Тодес. 05.01.1911-02.12.1989.

(„LS“) утвердилось название теория Лифшица-СлёзоваВагнера („LSW-theory“). Надо отдать должное Вагнеру, сам он не претендовал на отрытие этого метода.

Следует подчеркнуть, что явление коалесценции, или Оствальдовского созревания, является универсальным физическим законом. В той или иной форме эта стадия следует за стадией нуклеации (образования зародышей) и последующей стадией независимого роста практически при всех фазовых переходах первого рода.

Сочетание элегантности теоретического анализа, широчайшей области применимости теории и блестящего экспериментального подтверждения привело, без преувеличения, к мировой известности этой работы. Эта теория прочно вошла в арсенал физиков, работающих в области физики твердого тела и материаловедения. Изложение теории Лифшица-Слёзова содержится во многих учебниках и книгах, в частности, в известном курсе теоретической физики Ландау-Лифшица в десятом томе „Физическая кинетика“, написанном Е.М. Лифшицем и Л.П. Питаевским.

Работа [5] явилась основой кандидатской диссертации В.В. Слёзова, защищенной им в 1959 г., и во многом определила его дальнейшие научные интересы. Характерно, что вернувшись почти через 20 лет к задаче, рассмотренной в [5], он смог детально проанализировать сам процесс формирования (из достаточно общих начальных условий) универсальной функции распределения частиц новой фазы по размерам [9] и, тем самым, довел теорию до ее полного логического завершения. 
В работе над теорией переконденсации $[5,6,9]$ в полной мере проявилась способность Виталия Валентиновича использовать нестандартные подходы при решении поставленных физических задач. В последующих работах [10-16] развитый В.В. Слёзовым метод описания кинетики фазовых переходов первого рода был обобщен им на многокомпонентные многофазные системы. В обобщенной теории удалось учесть ряд существенных факторов, таких как влияние растворенного газа, взаимную экранировку диффузионных полей частиц новых фаз и такие внешние факторы, как облучение и механические нагрузки. Во всех этих случаях распада установлены асимптотические по времени законы роста частиц новой фазы и получены распределения их по размерам. Следующие из теории закономерности диффузионного распада хорошо подтверждаются экспериментально. Теория, построенная И.М. Лифшицем и В.В. Слёзовым, получила дальнейшее развитие в работах его учеников и последователей. Так, один из авторов этой статьи (С.А. Кукушкин) в дальнейшем построил теорию теплового Оствальдовского созревания, протекающую при кристаллизации расплавов [17], в дальнейшем обобщенную на случаи Оствальдовского созревания в многокомпонентных расплавах, в которых происходят одновременно и диффузионный массоперенос, и перенос тепла. Подробно были исследованы процессы Оствальдовского созревания в ансамблях многокомпонентных островковых пленок на поверхности твердых подложек. Эти процессы обобщены в книге [18]. Развитие теории Оствальдовского созревания, фундамент которой заложили И.М. Лифшиц и В.В. Слёзов в свой классической работе [5], не остановись со временем. Последователи и ученики В.В. Слёзова продолжают активно развивать это фундаментальное направление и в настоящее время [19].

Творчество Виталия Валентиновича многогранно и не ограничивалось только исследованиями процессов коалесценции. Так, в 60-е годы В.В. Слёзовым (совместно с А.М. Косевичем и З.К. Саралидзе) была развита теория диффузионно-дислокационного течения кристаллов под действием механической нагрузки [20,21], частным случаем которой является предложенная несколько позже теория ползучести металлов Набарро. В ее рамках был объяснен ряд наблюдаемых в эксперименте явлений, например, переориентация дислокационных петель в результате действия одноосной нагрузки, и предложено объяснение эффекта залечивания или роста пор при нагрузках выше пороговой. Была установлена зависимость скорости течения материала от внешней нагрузки и предложен метод определения скорости диффузионного роста пор и дислокационных петель при наличии объемных источников точечных дефектов (например, при радиационном облучении). Результаты, полученные при исследовании диффузионного распада твердых растворов и диффузионно-дислокационного течения кристаллов, составили содержание докторской диссертации В.В. Слёзова, которая была им защищена в 1969 г. С 1973 года он возглавил лабораторию, а с 1997 г. он стал начальником отдела УФТИ, в котором проводились теоретические исследования по физике конденсированного состояния, теории фазовых переходов и сверхпроводимости.

За работы по теории неидеальных кристаллов в 1978 г. В.В. Слёзову,совместно с А.А. Смирновым,М.А. Кривоглазом и А.М. Косевичем,была присуждена Государственная премия УССР в области науки и техники. В 1993 г. он стал лауреатом Государственной премии Украины за цикл работ „Фазовые и структурные превращения в твердых растворах с микро- и субмикронеоднородным распределением элементов и их использование для получения новых металлических материалов“ (совместно с А.М. Ивасишиным, В.Г. Гаврилюком, В.В. Кокориным и Р.В. Телевичем). В 1995 г. В.В. Слёзов избран членом-корреспондентом Национальной академии наук Украины.

В 1990-2000-е годы научные интересы Виталия Валентиновича смещаются в сторону исследования начальных стадий фазовых превращений первого рода, которые предшествуют асимптотической стадии, описываемой теорией Лифшица-Слёзова, а именно, стадии зарождения и переходной стадии. Им предложен новый подход к исследованию временной эволюции при фазовых превращениях в различных метастабильных системах [22,23]. С помощью этого подхода удалось описать как зарождение новой фазы,так и более длительную переходную стадию, причем не только в однокомпонентных, но и в многокомпонентных метастабильных системах. Таким образом, стало возможным полное описание эволюции таких систем при фазовых превращениях первого рода.

Характерной особенностью работ В.В. Слёзова на протяжении всей его творческой деятельности является их направленность на решение актуальных физических проблем, имеющих важное практическое значение [24]. $\mathrm{OH}$ всегда стремился работать в тесном контакте с физиками-экспериментаторами.

Основные результаты многолетней работы, незадолго до свой кончины В.В. Слёзов подытожил в монографии [25].

\section{Благодарности}

В заключениие хотелось бы поблагодарить организаторов и спонсоров нашей конференции. Организаторами конференции являлись Институт Проблем Машиноведения РАН (ИПМаш РАН), Лаборатория структурных и фазовых превращений в конденсированных средах, ООО „Научно-Технический Центр „Новые технологии“, ООО „Новые Кремниевые Технологии“ и СанктПетербургский Научный Центр РАН.

\section{Финансирование работы}

Основным спонсором конференции выступила компания ООО „Научно-Технический Центр „Новые технологии“. Финансовую поддержку также оказала компания „TESCAN Ltd.“. 


\section{Конфликт интересов}

Авторы заявляют об отсутствии конфликта интересов.

\section{Список литературы}

[1] Ф.Г. Басс, М.И. Каганов, В.В. Слёзов. ФММ 5, 406 (1957).

[2] М.И. Каганов, В.В. Слёзов. ЖЭТФ 32, 1496 (1957).

[3] О.М. Тодес. Кинетика коагуляции и укрупнения частиц в золях. В кн.: Проблемы кинетики и катализа. В. VII Статистические явления в гетерогенных системах. Изд-во АН СССР, М.-Л. (1949). С. 137-173.

[4] Ф.М. Куни, А.К. Щекин, А.П. Гринин. УФН 171, 345 (2001).

[5] И.М. Лифшиц, В.В. Слёзов. ЖЭТФ 35, 479 (1958).

[6] И.М. Лифшиц, В.В. Слёзов. ФТТ 1, 1401 (1959).

[7] I.M. Lifshits, V.V. Slyozov. J. Phys. Chem Solids19, 35 (1961).

[8] C. Wagner. Z. Electrochem. 65, 581 (1961).

[9] V.V. Slezov.J. Phys. Chem. Solids 39, 367 (1978).

[10] В.В. Слёзов, В.Б. Шикин. ФТТ 6, 7 (1964).

[11] З.К. Саралидзе, В.В. Слёзов. ФТТ 7, 904 (1965).

[12] З.К. Саралидзе, В.В. Слёзов. ФТТ 7, 1605 (1965).

[13] В.В. Слезов, Е.Ф. Тихонов. ДАН. 266, 619 (1982).

[14] В.В. Слезов. ФТТ. 36, 557 (1994).

[15] V.V. Slezov, V.B. Shikin. Euro Nuclear. 2, 127 (1965).

[16] В.В. Слёзов, В.В. Сагалович. УФН 151, 67 (1987).

[17] С.А. Кукушкин. ФТТ 27, 2987 (1985).

[18] С.А. Кукушкин, В.В. Слёзов. Дисперсные системы на поверхности твердых тел (эволюционный подход): механизмы образования тонких пленок. Наука, СПб. (1996). $304 \mathrm{c}$.

[19] С.А. Кукушкин, А.В. Осипов. ЖЭТФ 113, 2197 (1998).

[20] А.М. Косевич, 3.К. Саралидзе, В.В. Слёзов. ЖЭТФ 50, 958 (1966).

[21] В.В. Слёзов. ЖЭТФ 53,912 (1967).

[22] В.В. Слёзов. ФТТ42, 733 (2000).

[23] V.V. Slezov, J. Schmelzer. Phys. Rev. E 65, 031506 (2002).

[24] В.В. Слёзов, Л.Н. Давыдов, О.А. Осмаев, Р.В. Шаповалов. ВАНТ. Сер. ФРП и РМ. 3 (83),25 (2003).

[25] VV. Slezov. Kinetics of First-Order Phase Transitions. Weinheim: Wiley-VCH Publishers (2009). 429 p.

Редактор Д.В. Жуманов 